RUNNING HEAD: SOCIAL EXCLUSION AND DECISION-MAKING

\title{
Adaptive cooperation in the face of social exclusion
}

Lukasz Walasek $^{\mathrm{a}}$ Marie Juanchich $^{\mathrm{b}}$, and Miroslav Sirota ${ }^{\mathrm{b}}$

Authors' affiliations:

${ }^{a}$ University of Warwick, Department of Psychology

${ }^{\mathrm{b}}$ University of Essex, Department of Psychology

\section{Corresponding author:}

Lukasz Walasek

Address: Department of Psychology, University of Warwick, CV4 7AL, Coventry, UK.

Email: L.Walasek@warwick.ac.uk

Tel: (+44) 2476523523

Marie Juanchich

Address: Department of Psychology, University of Essex, Wivenhoe Park, CO4 3SQ,

Colchester, UK.

Email:m.juanchich@essex.ac.uk

Tel: (+44) 1206873812

Miroslav Sirota

Address: Department of Psychology, University of Essex, Wivenhoe Park, CO4 3SQ, Colchester, UK.

Email: msirota@essex.ac.uk

Tel: (+44) 1206874229

Note. This is an accepted manuscript version for an article to be published in the Journal of Experimental Social Psychology; the current version might differ slightly from the published version. 


\begin{abstract}
The extent to which socially excluded individuals are willing to collaborate with others is an important theoretical and practical question. We consider four contrasting predictions based on the existing psychological literature. The first two are derived from the need-threat literature: Following social rejection individuals may withdraw from cooperative interaction in general (aggression hypothesis), or cooperate more in general (reconnection hypothesis). Alternatively, performance of the excluded individuals in cooperative tasks may worsen reflecting reduced ability to deliberate (cognitive depletion hypothesis). Finally, excluded individuals may cooperate less with those who rejected them (revenge hypothesis). We tested these hypotheses in three incentivized experiments. In each, we first varied whether participants were excluded or included in a virtual ball-passing game. In the second part, participants entered a two-player investment game, in which their earnings were partly dependent on the cooperativeness of their partner. We varied how cooperative the co-player was, and measured whether our participants were willing to cooperate or not. All participants entered the game twice, once with an unknown player, and once with a person who they previously encountered during the ball-passing task. Our findings were consistent with the revenge hypothesis - excluded participants were less cooperative when they were paired with the individual who previously excluded them. Interactions with unknown players were unaffected - excluded and included participants were equally cooperative. We propose a straightforward explanation of our findings: People do not like to cooperate with those who previously rejected them, but the experience of rejection does not have broad implications for people's overall willingness to cooperate.
\end{abstract}

Key words: Social exclusion; Ostracism, Group dynamics, Cooperation, Psychological need, Trust, Aggression 


\section{Introduction}

A decision whether to cooperate or not is often driven by the social cues that inform us about the trustworthiness and cooperativeness of others (Declerck, Boone, \& Emonds, 2013). For example, try to remember the last negative interaction you had with someone. After this interaction, how likely were you to collaborate with the same person, as opposed to another person who you met for the very first time? It seems unlikely that memories of previous encounters would have no effect on people's choices (Stevens, Volstorf, Schooler, \& Rieskamp, 2011). In the present work, we set out to test how the experience of being socially rejected influences people's decisions to cooperate with others. In doing so, we extend existing work on ostracism which shows that socially excluded individuals suffer from a wide range of negative behavioural, cognitive, and emotional consequences (DeWall \& Bushman, 2011; Ren, Wesselmann, \& Williams, 2018; Williams, 2007; Williams \& Nida, 2011). More specifically, here we re-evaluate some of the inconsistent findings reported in the literature about the effects of being rejected on decision-making performance in a social setting.

\section{Exclusion and cooperation}

How could the experience of social rejection influence our willingness to cooperate with others? Possible answers are provided within the temporal need-threat framework, a dominant theoretical model of ostracism and its psychological consequences (Williams, 2009; Williams \& Nida, 2011). Within this model, the effects of being rejected are conceptualized as a sequence of automatic and deliberate responses. Exclusion first creates an immediate pain (reflexive stage) and in the following stage (reflective stage) exclusion threatens a range of basic human needs such as the need for belonging, self-esteem, feelings of control and meaningful existence. The corresponding emotions arising at this point are of anger and sadness. It is at the reflective stage that social exclusion may result in an array of 


\section{SOCIAL EXCLUSION AND DECISION MAKING}

behavioural responses. Importantly, whether a person reacts aggressively or in a prosocial manner depends on the needs that are most threatened. In order to recover from threats to need for control, people are expected to produce more aggressive reactions, while to recover from threats to belonging and self-esteem, people are expected to produce prosocial responses (Wesselmann, Ren, \& Williams, 2015). Since a typical experimental exclusion paradigm often result in the robust threat to all psychological needs described above, the exact response to social exclusion - aggression or reconnection - may then depend on a range of situational and personal factors (Nezlek, Wesselmann, Wheeler, \& Williams, 2012; Wesselmann et al., 2015).

According to the temporal need-threat framework, if excluded individuals seek to improve their self-esteem and feelings of belonging they should be more prosocial and hence cooperate more. Indeed, existing work shows that ostracised individuals pursue ways of reconnecting with others by being more prosocial and cooperative (Derfler-Rozin, Pillutla, \& Thau, 2010; Lyyra, Wirth, \& Hietanen, 2017; Maner, DeWall, Baumeister, \& Schaller, 2007). Maner and colleagues (2007) showed that rejected participants wanted to interact with others more and gave higher rewards to other participants. Interestingly, these authors found that excluded individuals sought to form bonds with new people, and not to reconnect with those who excluded them. In a similar vein, Derfler-Rozin et al. (2010) tested the effect of social exclusion in a game of trust and found that those who anticipated being excluded were more likely to entrust a larger amount of their money to other players. The amounts entrusted were larger than those offered by players who were given the prospect of social inclusion, or players who simply received a negative prospect regarding their health (to induce a negative mood). The authors explained this elevated propensity to take risks as an adaptive response, whereby displays of generosity and trust can be used to reconnect with people and rebuild 


\section{SOCIAL EXCLUSION AND DECISION MAKING}

social ties. Together, this evidence suggests that excluded individuals may be more likely to cooperate with other people in general.

An alternative possibility, and one that is also suggested by the temporal need-threat framework, is that excluded individuals become more aggressive in order to restore feelings of control and meaningful existence. Consistently, previous works shows that socially excluded individuals are less likely to help others (Twenge, Baumeister, DeWall, Ciarocco, \& Bartels, 2007) and behave aggressively towards other people (Ayduk, Gyurak, \& Luerssen, 2008; Riva, Romero Lauro, DeWall, Chester, \& Bushman, 2015; Warburton, Williams, \& Cairns, 2006). Ostracism has been shown to reduce cooperation with unknown individuals, even in tasks in which high cooperativeness is optimal (i.e. leads to highest monetary rewards) (Twenge et al., 2007, Experiments $4-6$ ).

A more nuanced version of the link between exclusion and aggressiveness is that the experience of being rejected alters one's behaviour towards the exclusion perpetrator only. Excluded individuals are indeed hostile towards those who rejected them (Buckley, Winkel, \& Leary, 2004; Twenge, Baumeister, Tice, \& Stucke, 2001), which should be expected given that people tend to channel their negative emotion and retaliate against people who offended them (McCullough, Kurzban, \& Tabak, 2013). It is therefore possible that excluded individuals become less cooperative towards the person(s) who excluded them, but that their level of cooperativeness towards others remains unchanged. Results consistent with such a targeted response to ostracism were reported by Hillebrandt, Sebastian, and Blakemore, (2011), who observed that ostracized individuals were less trusting towards those who rejected them, but as trusting towards strangers as participants who were included. It is not clear, however, how these results are related to the alternative aggressiveness and reconnection accounts, in which ostracism is expected to affect cooperation in general. 


\section{SOCIAL EXCLUSION AND DECISION MAKING}

In other research, social exclusion was independently shown to dampen cognitive executive functioning, such as memory or reasoning, which could also affect cooperation (Baumeister, DeWall, Ciarocco, \& Twenge, 2005; Baumeister, Twenge, \& Nuss, 2002; Hawes et al., 2012). However, the link between cognitive resources and cooperation is not straightforward. Some evidence suggest that when participants use fewer cognitive resources (i.e., deliberate less) they are more cooperative (Rand, Greene, \& Nowak, 2012), but others found evidence for the opposite (Achtziger, Alós-Ferrer, \& Wagner, 2016), or no effect at all (Bouwmeester et al., 2017; Verkoeijen \& Bouwmeester, 2014). For example, participants with higher cognitive reflection scores have been shown to invest more money in a one shot public good game (Lohse, 2016). Indeed, giving money away in an investment game may be a smart move with a cooperative investor, but it may not be the "intelligent" course of action with an uncooperative partner (Rand, 2016). Hence, building on the fact that social exclusion is expected to tax cognitive resources, exclusion should dampen the ability to be strategic in multiplayer games requiring coordination with other people. One could therefore expect that excluded individuals may perform worse in tasks requiring them to adjust their own level of cooperativeness in response to the behaviour of their partner.

In summary, based on the existing literature, it is unclear what effect social exclusion should have on the person's willingness to cooperate. Despite the breadth of research on the subject, distinct psychological responses to ostracism have been mainly studied in isolation. This is problematic since these mechanisms tend to be inconsistent with one another. According to the "aggression hypothesis", rejected individuals may be uncooperative, although it is unclear whether this behaviour would be limited to the exclusion perpetrator only ("revenge hypothesis"). Alternatively, the "reconnection hypothesis" states that exclusion promotes attempt to reconnect with others, which may manifest itself via heightened cooperativeness. Finally, if social exclusion leads to a depletion of cognitive 


\section{SOCIAL EXCLUSION AND DECISION MAKING}

resources ("cognitive depletion hypothesis"), cooperation might be affected depending on whether cooperation is an effective strategy or not. Both aggression and reconnection hypotheses are consistent with the temporal need-threat framework, such that either response is viable depending on which psychological needs are perceived to be most threatened. In this research, we extend previous literature by considering all of the abovementioned effects simultaneously as competing explanations of willingness to cooperate following exclusion.

\section{Current work}

The objective of the present work is to tease apart the four competing hypotheses about the effect of exclusion on cooperation. To achieve this, we investigated the role of social exclusion on decision-making performance in a cooperative environment. All three of our experiments consisted of two parts. In the first part, we manipulated social exclusion using the Cyberball paradigm (Williams \& Jarvis, 2006). All participants played the ball-passing game and were either included, receiving a fair share of passes, or excluded, receiving only a few passes from other players. This method is widely used in the literature, and has been shown to negatively impact the four basic psychological needs related to social exclusion (i.e. belonging, self-esteem, life meaning, sense of control) (Zadro, Williams, \& Richardson, 2004). In the second part, we measured cooperativeness in a task involving real monetary incentives. We designed a multi-round, two-player decision task, in which participants could invest money by transferring it to another person (i.e., a recipient) over the course of five rounds. The recipient was only identifiable by name, and was always male for consistency. In each round, the money invested was tripled before being received by a recipient. Our participants could anticipate that the recipient cooperates and returns more money, or that he is uncooperative and keeps all of the money. In the game, unbeknownst to the participants, the recipient was not a real player and his behaviours were predetermined by the 
experimenter. At the end of each round, participants learnt about the money they were sent back, hence learning how cooperative the recipient was.

$<$ Insert Figure 1 about here >

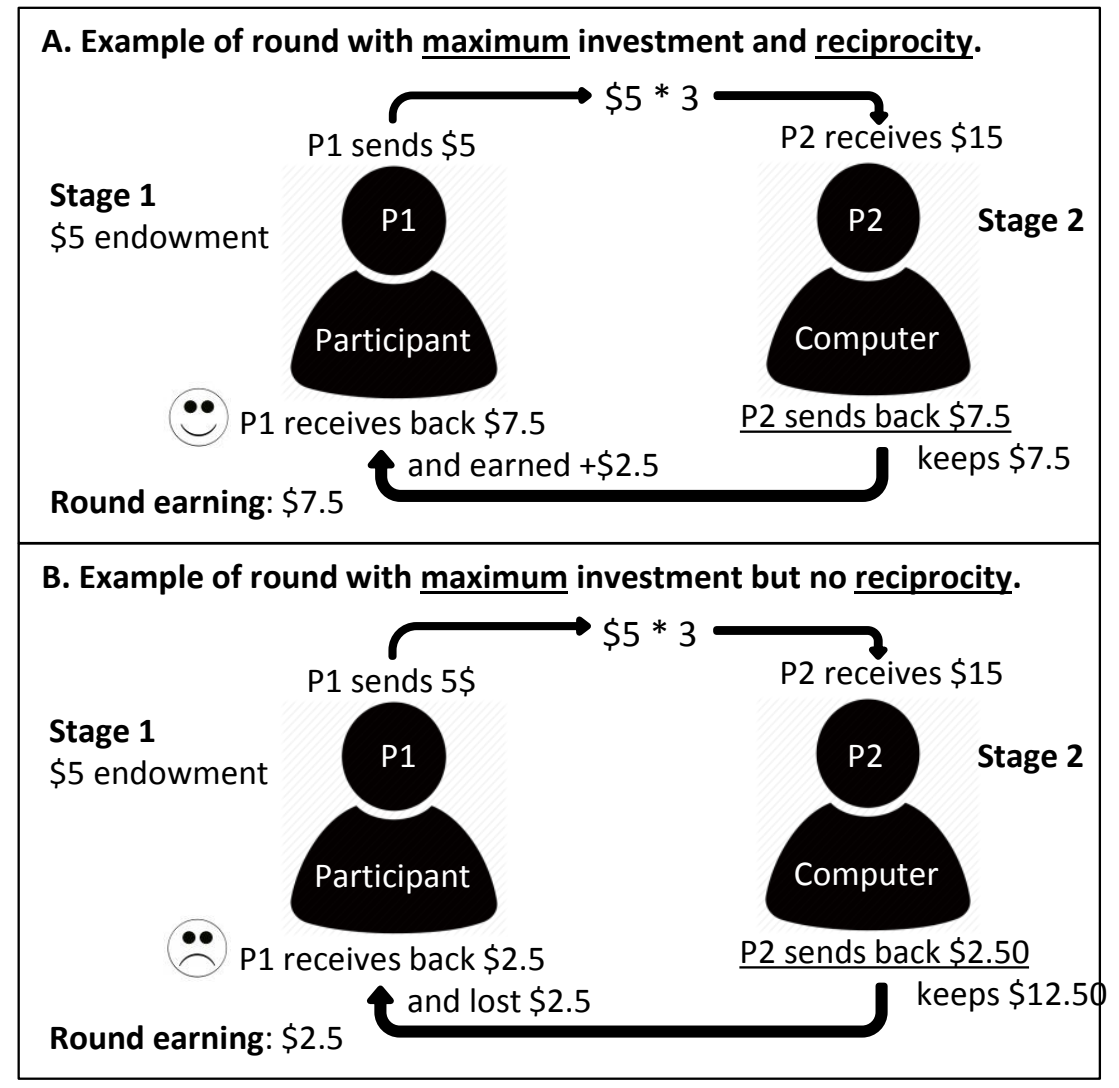

Figure 1. Procedure of the Investment Game and example of possible earnings according to the level of reciprocity (top panel: cooperative partner, bottom panel: uncooperative partner) of the decision-making partner.

In the original version of this game (Berg, Dickhaut, \& McCabe, 1995), participants did not receive any feedback about the behaviour of recipients, it was hence "risky" to entrust one's money, round after round, to someone who may be tempted to keep it all. In our version of the game, however, participants have the possibility to learn about their partner (i.e., how cooperative they are) and to strategically adapt their behaviour to maximise their 


\section{SOCIAL EXCLUSION AND DECISION MAKING}

profit. In all three studies, we controlled the prior experience our players had with their partners in the investment game. More specifically, our participants had to interact with two types of players: a player who they never encountered before, and a player who either did or did not exclude them in the preceding game of Cyberball. These modifications were central to testing our four competing hypotheses as we describe below.

Our versions of the investment game permits us to explore all four hypotheses concurrently. According to the reconnection hypothesis, excluded individuals will earn more money by being more cooperative when cooperativeness is optimal, but less money when cooperativeness is suboptimal. If they behave in line with the aggression hypothesis, people will simply choose to cooperate less after being rejected. Accordingly, we would expect that excluded individuals would earn less money by being less cooperative when cooperativeness is optimal, but more money when cooperativeness is suboptimal. According to the revenge hypothesis, earnings in the investment game should be affected in the same way, but only when people play with the person who previously rejected them, not when they interact with a stranger. Finally, the ability to adjust one's cooperativeness level in the investment game is critical for good performance. If cognitive resources are depleted on account of social exclusion, we would expect poorer performance among rejected individuals whatever the level of cooperation and whether the investment game partner is known or not. Predictions of these four hypotheses regarding the behaviour of excluded participants are summarized in Table 1.

In order to test all four hypotheses, we modified the payoff structure in our experiments. Specifically, our participants played the investment game with a cooperative (Experiment 1 and 2) and uncooperative partner (Experiment 3). The aggression and the lower cognitive resources hypotheses posit the same results in Experiments 1 and 2 - when participants played with a collaborative partner. Experiment 3 provides a context in which the 


\section{SOCIAL EXCLUSION AND DECISION MAKING}

two hypotheses lead to different patterns: when participants play with an uncooperative partner, we expect socially excluded participants to perform better according to the aggression hypothesis (as they cooperate less) and less well according to the lower cognitive resources. Further, the social reconnection hypotheses would be facilitated in Experiment 1 and 2 in which cooperating leads to higher earnings and hence Experiment 3 puts the same hypothesis to a more stringent test. Conversely, the aggression hypothesis may be dampened in Experiment 1 and 2 by the fact that not cooperating leads to personal loss, hence Experiment 3 represents a more appropriate setting to find evidence of such process. Finally, the revenge hypothesis posits that people should only change their investment decisions when interacting with the person who excluded them. In such a case, we would expect excluded participants to earn less with the cooperative player who excluded them in Experiment 1 and 2, but to earn more in Experiment 3.

<Insert Table 1 about here>

Table 1. Four hypotheses about the performance (money earned) in the investment game of the excluded participants.

\begin{tabular}{lll}
\hline & & Money earned \\
\hline $\mathrm{H}_{\text {Reconnection }}$ & Cooperation optimal (Exp 1,2) & \multicolumn{1}{c}{ Cooperation suboptimal (Exp 3) } \\
\hline $\mathrm{H}_{\text {Aggression }}$ & Earn more on average. & Earn less on average \\
\hline $\mathrm{H}_{\text {Revenge }}$ & Earn less when interacting with the & Earn more when interacting with the \\
& excluding participant only. & excluding participant only. \\
\hline $\mathrm{H}_{\text {Cognitive depletion }}$ & Earn less on average. & Earn less on average \\
\hline
\end{tabular}

\section{General methods for experiments 1, 2 and 3}

\section{The Cyberball game}




\section{SOCIAL EXCLUSION AND DECISION MAKING}

In three experiments, we induced feelings of social rejection using a virtual ball-tossing game paradigm (Zadro et al., 2004). Cyberball is an online ball-tossing game created to manipulate social exclusion (Williams \& Jarvis, 2006). In our studies, the game was introduced to participants with the stated aim of practising mental visualisation skills. The social manipulation was implemented according to the number of ball tosses that the participant received from the other two players who were computer animated. In the social inclusion condition, participants received the ball approximately 10 times out of 30 ball tosses throughout the game. In the exclusion condition, participants received 2 tosses at the beginning of the game and none of the remaining 28 ball tosses. In both conditions, participants played for an average of 2 minutes (the duration varied slightly according to how quickly participants sent the ball back).

\section{Post exclusion survey and checking measures}

Following on the past literature, we used four measures designed to assess the psychological impact of the ball-tossing game (Zadro et al., 2004). The questionnaire included perception of exclusion, four fundamental psychological needs, and mood (see Appendix A for the exact wording of each question). Perception of exclusion covered two aspects: feeling of exclusion, measured via two items, and the perceived number of ball tosses received during the game. The four fundamental needs were belongingness (e.g., I felt disconnected), self-esteem (e.g., I felt liked), feeling of control (e.g., I felt superior) and feeling of meaningful existence (e.g., I felt invisible), each of which was measured by three items with a five-point Likert scale ranging from 1: Not at all to 5: Very much. The participants' mood was measured with the short Positive and Negative Affect Schedule (PANAS, 10 items; Watson, Clark, \& Tellegen, 1988) with a 5-point Likert scale ranging from 1: Not at all to 5: Completely. Mood was computed by subtracting the average score for 
SOCIAL EXCLUSION AND DECISION MAKING

the five negative mood items from the average score for the five positive mood items (Juanchich, Walasek, \& Sirota, 2018).

Note that all experiments ended with a debriefing, after which everyone completed a self-esteem boost where they listed their best qualities followed by an assessment of their current mood and self-esteem. This was shown to effectively remedy the negative effect of social exclusion (Juanchich et al., 2018; Walasek, Matthews, \& Rakow, 2015). Finally, all participants reported whether they experienced any issues with the Cyberball game and if they had played Cyberball before. In addition, participants reported basic sociodemographic characteristics: gender, age, professional category, and ethnicity.

\section{The investment game}

The investment game was an adaptation of the Trust Game used by Berg et al. (1995). In the present experiment participants only played the role of the sender - their role was to decide how much money to send to the recipient who was their decision-making partner. This partner was introduced as a fellow student, but was in fact computer-based. The investment was multiplied by a factor of three and given to their decision-making partner.

Additionally we also manipulated the identity of the partner with whom our participants interacted. In all the experiments, our participants played with an unknown person first for 5 rounds and then with a person who was involved in the Cyberball game for another 5 rounds. This allowed us to evaluate the hypotheses that assume a global change in cooperation among excluded individuals (the reconnection and aggression hypotheses) and also the hypothesis that assumes a more targeted reaction (the revenge hypothesis). The instructions of the game provided to participants are available in Appendix B.

We also changed the reciprocity of the partner across experiments, so that we could investigate whether participants who were rejected were also able to adapt their investment 


\section{SOCIAL EXCLUSION AND DECISION MAKING}

strategy to maximise their profit. Figure 1 shows the structure of the investment game with a partner who showed a high level of reciprocity (top panel; as in Experiments 1 and 2) and a low level of reciprocity (bottom panel; as in Experiment 3). In Experiment 1 and 2, both partners were cooperative and send a fair amount of money back to the player. In Experiment 3 , the partner was not cooperative and only sent a small amount of money to the player (see Table 2, 5 and 6).

In all three experiments, we measured cooperativeness as the money earned by a participant in a round of the investment game. Note that this measure is highly correlated with the money invested (Pearson's $r=.990 ; .996$ and -.970 in Experiment 1, 2 and 3, respectively)

\section{Methodological statement}

We report all of the experiments we conducted on social decision-making and all of the variables measured. The experiments received the ethical approval of the University of Essex. For all the experiments, to test our hypotheses (as per Table 1), we reported statistical inference using frequentist null hypothesis testing and complemented it with Bayes Factors analysis that allowed us to quantify support for the null and alternative hypothesis. A Bayes Factor denotes the ratio of the probability of the data given model assumed by the null hypothesis to the probability of the data given model assumed by the alternative hypothesis. In generic terms, a $\mathrm{BF}$ of $\mathrm{BF}_{01}$, with a value of 1 indicates that the probability of data under $\mathrm{H}_{0}$ (meant here as a model assumed by $\mathrm{H}_{0}$ ) is as likely as under $\mathrm{H}_{1}$, (meant here as a model assumed by $\mathrm{H}_{1}$ ). Bayes factor with a value lower than 1 , indicates that the probability of data under $\mathrm{H}_{1}$ is more likely and a value greater than 1 indicates that the probability of data under $\mathrm{H}_{0}$ is more likely. These values can be interpreted in terms of evidential categories. We used here a categorization as follows: anecdotal (1 to 3 ), moderate (3 to 10$)$, strong (10 to 30 ), very strong (30 to 100) and extreme evidence (> 100) (Jeffreys, 1961; M. D. Lee \& Wagenmakers, 
SOCIAL EXCLUSION AND DECISION MAKING

2013). For instance, $\mathrm{BF}_{01}$ values between $>1$ and 3 represent "anecdotal evidence" in support of $\mathrm{H}_{0}$, whereas $\mathrm{BF}_{01}$ values $>100$ represent "extreme evidence" in support of $\mathrm{H}_{0}$. In order to obtain posterior odds (i.e., probability ratio of the two models after encountering data, or in other terms, a relative support of the models), one should update prior odds by Bayes Factor into posterior odds. These analyses were performed using JASP with default priors (JASP Team, 2018). A data screening procedure was followed consistently and is detailed in the Participants section of each experiment.

\section{Experiment 1}

In this experiment, the investment game was set so that the partner was always reciprocating more money than was initially entrusted, so it was always a good strategy to cooperate by investing more money. This procedure is exemplified in the first panel of Figure 1.

\section{Method}

Participants. A convenience sample of 199 first year psychology students from the University of Essex took part in the experiment in order to complete their research methods module.

Data screening. We removed data from two participants who reported problems with the survey. Our final sample size $(N=197)$ resulted in a power (sensitivity analysis) that would enable the experiment to detect a small to medium effect size of social exclusion (effect size $\mathrm{f}$ in $\mathrm{G}^{*}$ Power $=0.06$, power $=0.80$ ). Out of the 197 participants, most of the participants were women (81\%) and White Caucasian (57\%). Their ages ranged from 16 to 29 years $(M=19.01, S D=1.51)$. 
SOCIAL EXCLUSION AND DECISION MAKING

Design. The effect of social exclusion was tested in a mixed design in which we manipulated social exclusion as a between-subjects factor (inclusion vs. exclusion) and the decision-making partner as a within-subjects factor (unknown fellow student vs. Cyberball player). Participants made 10 decisions either after being included or excluded in the Cyberball game: 5 decisions with each decision partner. The order of the decision-making partner was fixed; participants played first with the unknown fellow student and then with one of the two Cyberball players. We reasoned that this ordering was best for testing the four possible consequences of exclusion: The aggression, reconnection and cognitive depletion hypotheses assume that social exclusion would have an effect on cooperation even if people played with strangers and only the revenge hypothesis posits that the effect will occur only with the known Cyberball player. Therefore, the most conservative test was to introduce that player last. The endowment given to participants at the beginning of each round along with the proportions of money given back in the five rounds were the same for each decisionmaking partner and were presented in the same fixed order. The endowments and the proportions of money given back are shown in the left part of Table 2 . Table 2 also summarizes different hypothetical pay-outs per round depending on the level of cooperation of participants.

<Insert Table 2 about here> 


\section{SOCIAL EXCLUSION AND DECISION MAKING}

Table 2. Structure of the investment game with levels of reciprocity in each round and total money earned in each round according to participants' strategies and to their partner's reciprocity in Experiment 1

\begin{tabular}{|c|c|c|c|c|c|c|c|}
\hline \multicolumn{4}{|c|}{ Round setup } & \multicolumn{4}{|c|}{$\begin{array}{l}\text { Investment examples and } \\
\text { corresponding money earned }\end{array}$} \\
\hline Partner & Round & Endowment & P2's Reciprocity & $£ 0$ & $£ 1$ & $50 \%$ & $100 \%$ \\
\hline \multirow{5}{*}{$\begin{array}{l}\text { Unknown } \\
\text { student }\end{array}$} & 1 & $£ 5.00$ & $* 150 \%$ & $£ 5.00$ & $£ 5.50$ & $£ 6.25$ & $£ 7.50$ \\
\hline & 2 & $£ 4.00$ & $* 130 \%$ & $£ 4.00$ & $£ 4.30$ & $£ 4.60$ & $£ 5.20$ \\
\hline & 3 & $£ 5.00$ & $* 140 \%$ & $£ 5.00$ & $£ 5.40$ & $£ 6.00$ & $£ 7.00$ \\
\hline & 4 & $£ 6.00$ & $* 150 \%$ & $£ 6.00$ & $£ 6.50$ & $£ 7.50$ & $£ 9.00$ \\
\hline & 5 & $£ 4.00$ & $* 140 \%$ & $£ 4.00$ & $£ 4.40$ & $£ 4.80$ & $£ 5.60$ \\
\hline \multirow{6}{*}{$\begin{array}{l}\text { Student } \\
\text { Cyberball } \\
\text { player }\end{array}$} & 1 & $£ 5.00$ & $* 150 \%$ & $£ 5.00$ & $£ 5.50$ & $£ 6.25$ & $£ 7.50$ \\
\hline & 2 & $£ 4.00$ & $* 130 \%$ & $£ 4.00$ & $£ 4.30$ & $£ 4.60$ & $£ 5.20$ \\
\hline & 3 & $£ 5.00$ & $* 140 \%$ & $£ 5.00$ & $£ 5.40$ & $£ 6.00$ & $£ 7.00$ \\
\hline & 4 & $£ 6.00$ & $* 150 \%$ & $£ 6.00$ & $£ 6.50$ & $£ 7.50$ & $£ 9.00$ \\
\hline & 5 & $£ 4.00$ & $* 140 \%$ & $£ 4.00$ & $£ 4.40$ & $£ 4.80$ & $£ 5.60$ \\
\hline & TOTAL & $\$ 48.00$ & $* 142 \%$ & $£ 48.00$ & $£ 52.20$ & $£ 58.30$ & $£ 68.60$ \\
\hline
\end{tabular}

\section{Results}

Checking the effect of the exclusion manipulation. Excluded participants reported receiving fewer ball tosses and feeling more excluded than included participants (see Table 3). Excluded participants also reported feeling lower levels of belonging, self-esteem, control and meaningful existence than included participants. The multivariate analysis of variance (MANOVA) tests assessing the effect of social exclusion on exclusion perceptions showed that there was a significant main effect of social exclusion condition, $F(9,187)=34.99$, $p<$ $.001, \eta_{\mathrm{p}}{ }^{2}=.63$. The between-subjects effects are listed in Table 3 and show that social exclusion had an expected effect on the psychological state of our participants. The debriefing and self-esteem boost intervention were successful. Mood and self-esteem levels reported by participants at the end of the questionnaire were no longer affected by the social exclusion manipulation. Only two of the participants had played the Cyberball game before, and we therefore did not include this variable as a covariate in our analysis. 
$<$ Insert Table 3 about here>

Table 3. Participants felt excluded and their basic needs were thwarted in the social exclusion condition.

\begin{tabular}{lccccc}
\hline & Cronbach's & Inclusion & Exclusion & Test & ES \\
\hline Experiment 1 & & & & $F(1,116)$ & $\eta p^{2}$ \\
Ball toss proportion & -- & $29.58(11.69)$ & $11.56(13.47)$ & $43.64 * * *$ & .28 \\
Feeling of exclusion & -- & $1.57(1.01)$ & $4.14(1.17)$ & $103.19^{* * *}$ & .48 \\
Feeling of belonging & .89 & $4.09(0.94)$ & $2.07(0.96)$ & $54.54 * * *$ & .34 \\
Self-esteem & .84 & $3.64(0.89)$ & $2.47(1.02)$ & $31.47 * * *$ & .24 \\
Feeling of control & .79 & $2.91(0.89)$ & $1.87(0.93)$ & $27.82^{* * *}$ & .20 \\
Meaningful existence & .87 & $4.00(0.83)$ & $2.37(1.08)$ & $58.68^{* * *}$ & .34 \\
Mood & .77 & $2.02(1.10)$ & $0.96(1.36)$ & $14.24 * * *$ & .11 \\
Post-debrief self-esteem & .84 & $4.00(0.75)$ & $3.69(0.91)$ & 1.44 & .01 \\
Post-debrief mood & .77 & $2.09(1.03)$ & $1.82(1.40)$ & $4.09 *$ & .03 \\
Experiment 2 & & & & $F(1,118)$ & $\eta_{\mathrm{p}}^{2}$ \\
\hline Ball toss proportion & -- & $32.03(7.79)$ & $10.66(14.26)$ & $76.20 * * *$ & .40 \\
Feeling of exclusion & -- & $1.59(0.87)$ & $4.15(1.17)$ & $164.71 * * *$ & .59 \\
Feeling of belonging & .93 & $3.83(0.69)$ & $2.26(1.08)$ & $10.46^{* * *}$ & .47 \\
Self-esteem & .90 & $3.53(0.92)$ & $2.48(0.92)$ & $22.94 * * *$ & .17 \\
Feeling of control & .83 & $2.95(0.90)$ & $1.80(0.91)$ & $36.44 * * *$ & .24 \\
Meaningful existence & .92 & $3.83(0.69)$ & $2.26(1.08)$ & $65.11^{* * *}$ & .35 \\
Mood & .78 & $1.77(1.19)$ & $1.26(1.25)$ & $9.08^{* *}$ & .07 \\
Post-debrief self-esteem & .87 & $3.73(0.90)$ & $3.75(0.83)$ & $<1$ & $<.01$ \\
Post-debrief mood & .76 & $1.88(1.24)$ & $1.84(1.07)$ & $<1$ & $<.01$ \\
Experiment 3 & & & & $F(1,118)$ & $\eta p^{2}$ \\
\hline Ball toss proportion & -- & $32.03(7.79)$ & $10.66(14.26)$ & $76.20 * * *$ & .40 \\
Feeling of exclusion & -- & $1.59(0.87)$ & $4.15(1.17)$ & $164.71 * * *$ & .59 \\
Feeling of belonging & .93 & $3.83(0.69)$ & $2.26(1.08)$ & $10.46 * * *$ & .47 \\
Self-esteem & .91 & $3.53(0.92)$ & $2.48(0.92)$ & $22.94 * * *$ & .17 \\
Feeling of control & .85 & $2.95(0.90)$ & $1.80(0.91)$ & $36.44 * * *$ & .24 \\
Meaningful existence & .90 & $3.83(0.69)$ & $2.26(1.08)$ & $65.11^{* * * *}$ & .35 \\
Mood & .81 & $1.77(1.19)$ & $1.26(1.25)$ & $9.08^{* * *}$ & .07 \\
Post-debrief self-esteem & .87 & $3.73(0.90)$ & $3.75(0.83)$ & $<1$ & $<.01$ \\
Post-debrief mood & .81 & $1.88(1.24)$ & $1.84(1.07)$ & $<1$ & $<.01$ \\
\hline & & & & & \\
\hline
\end{tabular}


SOCIAL EXCLUSION AND DECISION MAKING

Effect of social exclusion on decision-making performance. The participants' total earnings with the unknown and known decision-making partners are depicted in the top part of Table 4 according to the social exclusion condition.

\section{<Insert Table 4 about here>}

Table 4. Average total earnings in the investment game, with the unknown partner and with the Cyberball partner for included and excluded participants in experiments 1-3 along with cooperativeness perception in experiments 2 and $3(N=197,119$ and 117 for Experiments 1 , 2 and 3 respectively).

\begin{tabular}{|c|c|c|c|c|c|c|}
\hline & \multicolumn{3}{|c|}{ Unknown partner } & \multicolumn{3}{|c|}{ Cyberball partner } \\
\hline & Incl. & Excl. & t-test & Incl. & Excl. & t-test \\
\hline & $M(S D)$ & $M(S D)$ & & $M(S D)$ & $M(S D)$ & \\
\hline \multicolumn{7}{|l|}{ Experiment 1} \\
\hline \multirow{2}{*}{ Money earned } & 29.00 & 29.10 & \multirow{2}{*}{$t=-0.28, p=.793$} & 29.73 & 28.79 & \multirow{2}{*}{$t=2.61, p=.010$} \\
\hline & $(2.42)$ & $(2.36)$ & & $(2.39)$ & $(2.66)$ & \\
\hline
\end{tabular}

Experiment 2

\begin{tabular}{|c|c|c|c|c|c|c|}
\hline Money earned & $\begin{array}{l}24.69 \\
(1.55)\end{array}$ & $\begin{array}{l}24.71 \\
(1.42)\end{array}$ & $t=-0.05, p=.963$ & $\begin{array}{l}25.22 \\
(1.48)\end{array}$ & $\begin{array}{l}24.52 \\
(1.55)\end{array}$ & $t=2.38, p=.019$ \\
\hline Cooperativeness & $\begin{array}{c}3.35 \\
(0.90)\end{array}$ & $\begin{array}{c}3.61 \\
(0.84)\end{array}$ & $t=-1.58, p=.116$ & $\begin{array}{c}3.40 \\
(0.85)\end{array}$ & $\begin{array}{c}2.83 \\
(1.14)\end{array}$ & $t=3.10, p=.002$ \\
\hline
\end{tabular}

Experiment 3

\begin{tabular}{|c|c|c|c|c|c|c|}
\hline Money earned & $\begin{array}{l}21.70 \\
(1.81)\end{array}$ & $\begin{array}{l}21.25 \\
(2.07)\end{array}$ & $t=1.27, p=.206$ & $\begin{array}{l}22.00 \\
(1.75)\end{array}$ & $\begin{array}{l}22.15 \\
(1.77)\end{array}$ & $t=-0.47, p=.641$ \\
\hline Cooperativeness & $\begin{array}{c}2.70 \\
(1.03)\end{array}$ & $\begin{array}{c}2.82 \\
(1.07)\end{array}$ & $t=-0.62, p=.538$ & $\begin{array}{c}2.65 \\
(0.99)\end{array}$ & $\begin{array}{c}2.41 \\
(0.92)\end{array}$ & $t=1.36, p=.177$ \\
\hline
\end{tabular}

With the unknown decision-making partner, socially included and excluded participants played similarly and hence they earned just as much money. In contrast, with the known 


\section{SOCIAL EXCLUSION AND DECISION MAKING}

(former Cyberball) player, participants who had been excluded gave less money than included participants, and hence earned less. We tested the effect of social exclusion and history with the decision-making partner on decision-making by conducting a mixed-design analysis of variance (ANOVA) with social exclusion as the independent between-subjects variable (two levels: excluded vs. included) and decision-making partner as the withinsubjects variable (two levels: unknown vs Cyberball player). The results showed a significant interaction effect of social exclusion and decision-making partner, $F(1,195)=13.45, p<$ $.001, \eta_{\mathrm{p}}{ }^{2}=.06$. The main effects of social exclusion and decision-making partner were not significant, with $F(1,195)=1.73, p=.190, \eta_{\mathrm{p}}^{2}=.01$ and $F(1,195)=2.24, p=.136, \eta_{\mathrm{p}}^{2}=$ .01 , respectively.

We tested the main effect of social exclusion, decision-making partner and their interactions using a Bayes factor analysis. The Bayes factor analysis yielded strong evidence to support the interaction model (including social exclusion, decision-making partner and their interaction): the model including interaction (denoted as 2 in the subscript) was strongly preferred to the null model, $\mathrm{BF}_{20}=10.35$ and was very strongly preferred to the main effects model by a factor of $\mathrm{BF}_{21}=73.93$. This means that the data we observed were 10 times more likely if we assumed that social exclusion interacted with the identity of the decision-making partner (in addition to have a main effect) than if we assumed none of these variables had an effect and 74 times more likely than if we assumed that social exclusion and decision-making partner had only a main effect.

Further, the null model (including intercept only) was preferred to the two main effects model and to the model which featured only the main effect of social exclusion, $\mathrm{BF}_{10}=0.14$ and $\mathrm{BF}_{10}=0.49$ hence providing moderate and anecdotal evidence that social exclusion did not have a main effect on decision performance. 
SOCIAL EXCLUSION AND DECISION MAKING

Another way of assessing the impact of our manipulation is to look at the relation between psychological needs and money earned when interacting with a known and unknown player. In the supplementary materials, we report correlations between scores on all psychological needs and earnings made by excluded and included participants (for all three experiments independently). Overall, these results are consistent with the results of the ANOVAs reported above.

\section{Discussion}

The results of Experiment 1 show that excluded individuals entrusted less of their money to their decision-making partner when he was the exclusion perpetrator, and therefore earned less than included ones. In contrast, when participants played with a new partner, social exclusion did not affect their cooperation level and their earnings. These results are in contrast with the hypotheses that rejected individuals would show a general unwillingness to cooperate or a heightened cooperation (in order to reconnect with others). This finding also suggests that it is unlikely that excluded individuals suffered from a general impairment of deliberate reasoning because included and excluded individuals managed to earn the same amount of money when they interacted with the stranger. In contrast, the result supports the revenge hypothesis. Excluded individuals were unwilling to cooperate with the known Cyberball player even when it was costly. To test the robustness of the findings, we set out to replicate this experiment with a new and more diverse sample of participants and a lower level of cooperativeness of the partner.

\section{Experiment 2}

\section{Method}

Participants. We estimated the required sample size based on the effect observed in Experiment $1\left(\right.$ Partial $\left.\eta^{2}=.06\right)$, hence we aimed to recruit at least 106 responses. We adjusted 
SOCIAL EXCLUSION AND DECISION MAKING

this number upward to account for the possibility of having to discard some of the online data (+20\%), which left us with a target sample size of 127 .

Data screening. A total of 131 individuals from the Amazon Mechanical Turk platform took part in this experiment. In total we excluded incomplete responses $(n=1)$, cases based on completion time (+/- 2 SD from the completion mean were excluded, $n=5)$ and six for taking part in previous experiments we ran using the Cyberball game. None of the participants took part twice in the survey. None of the participants reported experiencing problems with the Cyberball game. Finally, out of those 119 participants, 28 reported that they had played Cyberball in the past. To assess whether Cyberball experience should be used as a covariate, we tested whether it had a main or interaction effect on needs and mood. Results showed that the interaction effect was not significant, $F(5,115)<1$. So, overall, our sample size $(N=119)$ resulted in a power (sensitivity analysis) that would enable the experiment to detect a small effect size $(f=0.08$, power $=0.80)$ which is enough to detect an effect like the one observed in Experiment 1).

Out of the 119 participants, the sample was fairly balanced in terms of gender (54\% men). Most participants were White Caucasian (79.5\%) and had achieved at least some College degree $(61 \%)$. Their ages ranged from 18 to 73 years $(M=34.74, S D=10.46)$.

Design. The design was the same as Experiment 1 - only the level of reciprocity of the decision-making partner in the investment game was adjusted.

Materials and procedure. This experiment featured the same materials as Experiment 1, except that the pounds were changed into dollars and that the payback rates were adapted, so that they were more varied. Decision-making partners reciprocated the investment in four out of five rounds ( $+30 \%$ to $+50 \%$ ) but did not give back any money in round 3 (see Table 4 ). In this set-up, cooperation was still optimal overall but less transparent (as compared to 


\section{SOCIAL EXCLUSION AND DECISION MAKING}

Experiment 1). The incentive to perform well in the money game was that two participants would be randomly selected to receive the earnings of one of the rounds (up to $\$ 9$ ).

\section{$<$ Place Table 5 about here >}

Table 5. Structure of the investment game with levels of reciprocity in each round and total money earned in each round according to participants' strategies and to their partner's reciprocity in Experiment 2.

\begin{tabular}{|c|c|c|c|c|c|c|c|}
\hline \multicolumn{4}{|c|}{ Round setup } & \multicolumn{4}{|c|}{$\begin{array}{l}\text { Investment examples and } \\
\text { corresponding money earned }\end{array}$} \\
\hline Partner & Round & Endowment & P2's Reciprocity & $£ 0$ & $£ 1$ & $50 \%$ & $100 \%$ \\
\hline \multirow{5}{*}{$\begin{array}{l}\text { Unknown } \\
\text { student }\end{array}$} & 1 & $£ 5.00$ & $* 150 \%$ & $\$ 5.00$ & $\$ 5.50$ & $\$ 6.25$ & $\$ 7.50$ \\
\hline & 2 & $£ 4.00$ & $* 150 \%$ & $\$ 4.00$ & $\$ 4.50$ & $\$ 5.00$ & $\$ 6.00$ \\
\hline & 3 & $£ 5.00$ & $* 0 \%$ & $\$ 5.00$ & $\$ 4.00$ & $\$ 2.50$ & $\$ 0.00$ \\
\hline & 4 & $£ 6.00$ & $* 130 \%$ & $\$ 6.00$ & $\$ 6.30$ & $\$ 6.90$ & $\$ 7.80$ \\
\hline & 5 & $£ 4.00$ & $* 150 \%$ & $\$ 4.00$ & $\$ 4.50$ & $\$ 5.00$ & $\$ 6.00$ \\
\hline \multirow{6}{*}{$\begin{array}{l}\text { Student } \\
\text { Cyberball } \\
\text { player }\end{array}$} & 1 & $£ 5.00$ & $* 150 \%$ & $\$ 5.00$ & $\$ 5.50$ & $\$ 6.25$ & $\$ 7.50$ \\
\hline & 2 & $£ 4.00$ & $* 150 \%$ & $\$ 4.00$ & $\$ 4.50$ & $\$ 5.00$ & $\$ 6.00$ \\
\hline & 3 & $£ 5.00$ & $* 0 \%$ & $\$ 5.00$ & $\$ 4.00$ & $\$ 2.50$ & $\$ 0.00$ \\
\hline & 4 & $£ 6.00$ & $* 130 \%$ & $\$ 6.00$ & $\$ 6.30$ & $\$ 6.90$ & $\$ 7.80$ \\
\hline & 5 & $£ 4.00$ & $* 150 \%$ & $\$ 4.00$ & $\$ 4.50$ & $\$ 5.00$ & $\$ 6.00$ \\
\hline & TOTAL & $\$ 48.00$ & $* 142 \%$ & $\$ 48.00$ & $\$ 49.60$ & $\$ 51.30$ & $\$ 54.60$ \\
\hline
\end{tabular}

Note: Pay back: \% of money given back by player 2 out of the money invested by participants.

Additionally, in this experiment, participants assessed how cooperative decisionmaking partners had been by providing their level of agreement with the following four statements for each decision-making partner: Jeff (Matt) cooperated well with me; Jeff (Matt) was a reliable partner in the game; Jeff (Matt) gave back a fair amount of money and Jeff (Matt) deserved to be trusted. Participants provided their judgment on a 5-point scale ranging from 1: I completely disagree to 5: I completely agree. The scale had a satisfactory level of reliability for the two decision-making partners: $\alpha$ Jeff $=.91$ and $\alpha$ Matt $=94$.

\section{Results}


SOCIAL EXCLUSION AND DECISION MAKING

Checking the effect of the exclusion manipulation. Excluded participants reported receiving fewer ball tosses and feeling more excluded than included participants (see Table 3). Further, excluded participants reported feeling lower levels of belonging, self-esteem, control and meaningful existence than included participants. The multivariate tests assessing the effect of social exclusion and Cyberball experience on exclusion perceptions showed that social exclusion had a main effect on the perception of exclusion, $F(7,107)=16.75, p<.001$, $\eta_{\mathrm{p}}{ }^{2}=.52$. The between-subjects effects are shown in Table 3 and indicate that the manipulation affected all the checking measures. Out of all the participants, 28 had experienced Cyberball before. Cyberball experience did not have either a main or an interaction effect on social exclusion perceptions, $F(7,107)<1, \eta_{\mathrm{p}}^{2}=.06$ and $F(7,107)=$ $1.25, p=.283, \eta_{\mathrm{p}}{ }^{2}=.08$. Cyberball experience was therefore not used as a covariate in subsequent analyses. The debriefing and self-esteem boost intervention were successful. Considering the effect size, it is clear that the effect of social exclusion was reduced considerably (from .10 to .03, see Table 3).

Effect of social exclusion on earnings and cooperation perception. The earnings of the participants with the unknown and known decision-making partners are depicted in Table 4 according to social condition along with the aggregate judgments of partners' cooperativeness. When they invested with the unknown partner, participants invested similarly whether they had been included or excluded, and therefore they earned just as much money. In contrast, when they played with the known (former Cyberball player) partner, participants who had been excluded gave less money than the included participants, and therefore earned less money. The results of the perceived cooperativeness of the partner were in line with these findings - excluded individuals perceived the known player to be less cooperative than those who were included in the game of Cyberball. 


\section{SOCIAL EXCLUSION AND DECISION MAKING}

We tested the effect of social exclusion and previous history with the decision-making partner by conducting a mixed-design ANOVA with social exclusion as the independent between-subjects variable (two levels: included vs. excluded) and decision-making partners as the within-subjects variable (two levels: unknown vs. Cyberball player) separately for money earned and cooperativeness perception as the dependent variables. The results of the ANOVA showed a significant interaction effect of social exclusion and decision-making partner for earning and cooperation perception, $F(1,117)=5.66, p=.019, \eta_{\mathrm{p}}{ }^{2}=.05$ and $F(1$, $117)=24.54, p<.001, \eta_{\mathrm{p}}{ }^{2}=.17$, respectively. The results also showed a significant main effect of the decision-making partner on money earned and cooperation perception. Participants earned more money with the unknown player than with the known player but they felt that the unknown player was more cooperative than the known player, $F(1,117)=$ $1.34, p=.250, \eta_{\mathrm{p}}{ }^{2}=01, F(1,117)=19.37, p<.001, \eta_{\mathrm{p}}{ }^{2}=.14$. Finally, there was no main effect of social exclusion on money earned and cooperation perception, $F(1,117)=2.02, p=$ $.158, \eta_{\mathrm{p}}{ }^{2}=02, F(1,117)=1.11, p=.294, \eta_{\mathrm{p}}{ }^{2}=.01$, respectively.

We tested the main effect of social exclusion, decision-making partner and their interactions using a Bayes factor analysis. The Bayes factor analysis yielded anecdotal evidence regarding the interaction model: the interaction model was preferred to the main effects model by a factor of $\mathrm{BF}_{21}=2.58$ but was not preferred to the null model, $\mathrm{BF}_{10}=0.35$. This result provides weaker support than that reported in Experiment 1, and this is likely due to the changed payoff structure in our investment task. Further, the null model (including intercept only) was preferred to the two main effects model, $\mathrm{BF}_{10}=0.14$ as well as to the model which featured only the main effect of social exclusion, $\mathrm{BF}_{10}=0.52$, or the main effect of the decision-making partner, $\mathrm{BF}_{10}=0.26$.

\section{Discussion}


SOCIAL EXCLUSION AND DECISION MAKING

Results of Experiment 2 were consistent with the first Experiment, showing that excluded participants were able to make as good investment decisions as those who were included when they played with an unknown individual. This is not consistent with the aggression and the reconnection hypotheses. However, in line with the revenge hypothesis, the results show that when they invested with the Cyberball player, excluded participants did not invest as well as included participants and consequently earned less. Social exclusion also had an impact on the perception of cooperativeness of the investment game partners. After being excluded, participants felt that the exclusion perpetrator was less cooperative, despite the fact that this player was in fact as cooperative as the unknown player. We did not find that socially excluded individuals performed worse than included participants in terms of overall money earned. As such, our results do not align with the idea that exclusion dampens intelligent thoughts - both excluded and included participants were capable of adjusting their contributions according to the perceived cooperativeness of the partner.

In order to further test the robustness of our findings, in Experiment 3 we modified the investment game so that the virtual decision-making partners consistently failed to reciprocate the money given to them (see example panel B in Figure 1). In this version of the investment game, the earning maximising strategy was to avoid investing any money altogether. If social exclusion lowers one's willingness to cooperate (i.e., aggression hypothesis), then this should be reflected in higher earnings, since non-cooperation is optimal. If, on the other hand, social exclusion encourages cooperative behaviour (reconnection hypothesis) the earnings should be lower. According to the revenge hypothesis, participants would earn more with the known decision-making player than with the unknown one with whom they would be more likely to cooperate. Finally, if excluded individuals suffer from reduced cognitive resources, then their earnings should be lowered since they would not be able to adjust their investment to reflect the non-cooperative nature of the game. 
SOCIAL EXCLUSION AND DECISION MAKING

\section{Experiment 3}

\section{Method}

Participants. Based on the effect observed in Experiment 1 (Partial $\left.\eta^{2}=.06\right)$ we planned to collect 106 responses. We adjusted the number upward to account for the possibility of having to discard some cases (+20\%) and arrived at a sample size of 127 .

Data screening. A total of 127 participants from Amazon Mechanical Turk took part in the study. We excluded a total of eight participants based on completion duration $(n=2)$, reported problems with Cyberball or the investment game $(n=4)$, repeater participants in the same experiment $(n=0)$ and participants who took part in previous experiments we ran with the Cyberball game $(n=2)$. So, overall, our sample size $(N=119)$ resulted in a power that would enable the experiment to detect a small effect size $\left(\right.$ Partial $\eta^{2}=0.22$, power $\left.=0.80\right)$ which is enough to detect an effect like the one observed in Experiment 1.

Out of the 119 participants, the sample has a majority of men (60.5\% men). Most participants were White Caucasian (79.8\%) and had achieved at least some College degree (73.1\%). Their ages ranged from 20 to 63 years $(M=34.18, S D=9.04)$.

Design. The design was the same as Experiments 1 and 2, we only changed the level of reciprocity of the investment game partner.

Procedure and materials. This experiment featured the same materials and procedure as in Experiment 2, except that the reciprocity level of the investment game partner was low. In this version of the game the decision-making partner kept most of the money that participants invested, meaning that the more participants invested, the lower their earnings would be. In rounds 1, 3 and 5, participants received less than what they had invested and in rounds 2 and 4 participants received their investment back without any earnings (see Table 
6). Not cooperating was clearly a better strategy to maximise earnings given low reciprocity levels.

< Place Table 6 about here >

Table 6. Structure of the investment game with levels of reciprocity in each round and total money earned in each round according to participants' strategies and to their partner's reciprocity in Experiment 3.

\begin{tabular}{|c|c|c|c|c|c|c|c|}
\hline \multicolumn{4}{|c|}{ Round setup } & \multicolumn{4}{|c|}{$\begin{array}{l}\text { Investment examples and } \\
\text { corresponding money earned }\end{array}$} \\
\hline Partner & Round & Endowment & P2's Reciprocity & $£ 0$ & $£ 1$ & $\mathbf{5 0 \%}$ & $100 \%$ \\
\hline \multirow{5}{*}{$\begin{array}{l}\text { Unknown } \\
\text { student }\end{array}$} & 1 & $£ 5.00$ & $*_{-} 50 \%$ & $\$ 5.00$ & $\$ 4.50$ & $\$ 6.25$ & $\$ 2.50$ \\
\hline & 2 & $£ 4.00$ & $* 100 \%$ & $\$ 4.00$ & $\$ 4.00$ & $\$ 5.00$ & $\$ 4.00$ \\
\hline & 3 & $£ 5.00$ & $*_{-50 \%} \#$ & $\$ 5.00$ & $\$ 4.50$ & $\$ 2.50$ & $\$ 2.50$ \\
\hline & 4 & $£ 6.00$ & $* 100 \%$ & $\$ 6.00$ & $\$ 6.00$ & $\$ 6.90$ & $\$ 6.00$ \\
\hline & 5 & $£ 4.00$ & $*_{-50 \%}$ & $\$ 4.00$ & $\$ 3.50$ & $\$ 5.00$ & $\$ 2.00$ \\
\hline \multirow{6}{*}{$\begin{array}{l}\text { Student } \\
\text { Cyberball } \\
\text { player }\end{array}$} & 1 & $£ 5.00$ & $*-50 \%$ & $\$ 5.00$ & $\$ 4.50$ & $\$ 6.25$ & $\$ 2.50$ \\
\hline & 2 & $£ 4.00$ & $* 100 \%$ & $\$ 4.00$ & $\$ 4.00$ & $\$ 5.00$ & $\$ 4.00$ \\
\hline & 3 & $£ 5.00$ & $*_{-} 50 \%$ & $\$ 5.00$ & $\$ 4.50$ & $\$ 2.50$ & $\$ 2.50$ \\
\hline & 4 & $£ 6.00$ & $* 100 \%$ & $\$ 6.00$ & $\$ 6.00$ & $\$ 6.90$ & $\$ 6.00$ \\
\hline & 5 & $£ 4.00$ & $*_{-5} 50 \%$ & $\$ 4.00$ & $\$ 3.50$ & $\$ 5.00$ & $\$ 2.00$ \\
\hline & TOTAL & $\$ 48.00$ & $*_{-30 \%}$ & $\$ 48.00$ & $\$ 45$ & $\$ 41.00$ & $\$ 34.00$ \\
\hline
\end{tabular}

Note: Pay back: \% of money given back by player 2 out of the money invested by participants.

\section{Results}

Checking the effect of the exclusion manipulation. Excluded participants reported receiving fewer ball tosses and feeling more excluded than included participants (see Table 3). Further, excluded participants reported feeling lower levels of belonging, self-esteem, control and meaningful existence than included participants. The multivariate tests assessing the effect of social exclusion and Cyberball experience on exclusion perceptions showed a main effect of being rejected, $F(7,109)=25.47, p<.001, \eta_{\mathrm{p}}{ }^{2}=.62$. The between-subjects 


\section{SOCIAL EXCLUSION AND DECISION MAKING}

effects indicated that the manipulation affected all the checking measures. Out of the 119 participants, 31 had previously experienced Cyberball. Cyberball experience did not have a main or an interaction effect on the social exclusion perceptions, $F(7,109)=1.89, p=.077$, $\eta_{\mathrm{p}}{ }^{2}=.11$ and $F(7,109)=1.13, p=.349, \eta_{\mathrm{p}}{ }^{2}=.07$. Cyberball experience was therefore not used as a covariate in subsequent analyses. The debriefing and self-esteem boost interventions were successful (see Table 3).

\section{Effect of social exclusion and decision-making partner on earnings and perceived}

cooperation. The money earned and cooperation perceptions are shown in the last rows of Table 4. As in Experiment 1 and 2, we performed a mixed ANVOA with social exclusion as the independent between-subjects variable (two levels: excluded vs. included) and decisionmaking partner as the within-subjects variable (two levels: unknown vs Cyberball player). Results showed a main effect of decision-making partner on money earned and cooperation perception, $F(1,117)=26.90, p<.001, \eta_{\mathrm{p}}^{2}=.19 ; F(1,117)=8.68, p=.004, \eta_{\mathrm{p}}^{2}=.07$. Furthermore, social exclusion interacted with decision-making partner to determine money earned and cooperation perception $F(1,117)=6.88, p<.001, \eta_{\mathrm{p}}^{2}=.06$ and $F(1,117)=5.45$, $p=.021, \eta_{\mathrm{p}}{ }^{2}=.04$. The meaning of the interaction is opposite to that in the previous experiments. The interaction reveals that with the unknown decision-making partner, excluded participants earned less than included participants but felt that the partner was more cooperative. In contrast, with the known partner, excluded participants earned slightly more than included participants but felt that the partner was less cooperative. However, note that the pairwise comparisons reported in Table 4 are not significant such there was no evidence that money earned and rated cooperativeness differed between excluded and included participants.

The Bayes factor analysis yielded evidence to support the interaction model, which was extremely preferred to the null model, $\mathrm{BF}_{20}=6369.74$ and moderately preferred to the main 
SOCIAL EXCLUSION AND DECISION MAKING

effects model, $\mathrm{BF}_{21}=4.59$. The model featuring the main effect of social exclusion was not preferred to the null model, $\mathrm{BF}_{10}=0.35$, but the model with the main effects of both social exclusion and decision-making partner was preferred to the null model, $\mathrm{BF}_{10}=1387.73$. More importantly, the Bayesian analyses hence also support the fact that the effect of social exclusion on decision-making performance in the investment game depended on the role of the player.

\section{Discussion}

The results of Experiment 3 are consistent with the findings of Experiments 1 and 2, in that we found a significant interaction between the Cyberball experience and partner's identity in the investment game. These results show that excluded individuals were less cooperative, but only when interacting with the person they encountered during the Cyberball game. Unlike previous studies, this behaviour led to higher earnings among excluded participants since investing large amounts of money was not optimal. However, the effect was small in magnitude, and pairwise comparisons of the money earned and rated cooperativeness were not significant. We return to this issue in the General Discussion section.

\section{General Discussion}

The objective of the present paper was to evaluate how the experience of being socially excluded influence people's ability to decide whether to cooperate with others. In our social decision-making task, cooperation was either an optimal (Experiment 1 and 2) or suboptimal (Experiment 3) strategy. Our results revealed that the experience of ostracism impacts people's behaviour on the investment task only when they are partnered with the person who was responsible for their exclusion. Exclusion had an effect on investment strategy even if the strategy was personally costly. When our participants believed that they were interacting 


\section{SOCIAL EXCLUSION AND DECISION MAKING}

with a new and unknown person, their behaviour was the same regardless of whether they were previously excluded or not. Thus, despite the fact the exclusion had a negative impact on various psychological needs and people's mood, their willingness to entrust money to another individual remained unaffected.

Our work was motivated by the predictions of the temporal need-threat framework, as well as various findings about the effects of social exclusion reported in the social psychology literature. A number of researchers have put forward elaborate cognitive and emotional mechanisms explaining how people's cooperation is influenced by the experience of being ostracized. However, existing research does not offer a simple answer to the consequences of social rejection in a social decision-making context: heightened or lowered cooperation; targeted or generalised changes in behaviour (Derfler-Rozin et al., 2010)? The design of our investment scenarios allowed us to test several alternative explanations, including the hypothesis of a withdrawal from cooperating with others (Twenge et al., 2007, 2001), a need to revenge exclusively against the exclusion perpetrator, a need to reconnect with other people (Derfler-Rozin et al., 2010; Maner et al., 2007) and a reduction of cognitive resources (Baumeister et al., 2002). Our findings support the revenge hypothesis and showed that excluded decision-makers were capable of adapting their strategy selection: investing was not considered to be a good strategy when collaborating with a person who had not "played fair" a few minutes before. Overall, our results are in line with original findings from the investment games showing that investment decisions are influenced by the previous interactions of participants with their partners (Berg et al., 1995). Our findings are also consistent with the results reported by Hillebrandt, Sebastian and Blakemore (2011). In a series of trust games, the authors showed that participants who experienced social exclusion in the game of Cyberball were less trusting towards the same players, but as trusting towards strangers as participants who were not excluded in the ball tossing game. A similar 


\section{SOCIAL EXCLUSION AND DECISION MAKING}

observation was made by Twenge et al. (2001), who report on a series of studies in which excluded participants would not show aggressive responses towards a friendly stranger. However, they also found that aggressiveness towards excluding individuals would spill over onto neutral others. In our own experiments, the stranger could be interpreted as friendly in Experiment 1 and 2, since they were highly cooperative throughout the course of the game. However, even when they were non-cooperative, excluded and included participants invested the same amount of money. We therefore did not observe any spill over effects - excluded and included participants behaved the same regardless of the cooperativeness of the stranger.

We must note that while we found evidence for the interaction model using both frequentist and Bayesian analysis, the effects were rather small in absolute terms. In fact, pairwise comparisons in Experiment 3, where cooperation was suboptimal, did not reveal any significant differences between excluded and included participants. Taken together, we should be cautious in interpreting the evidence that ostracized individuals are less cooperative towards those who excluded them.

The existing models of the effect of social exclusion on cooperation make various assumptions about the cognitive and affective processes that are influenced by the experience of ostracism. The dominant view is that of the temporal need-threat framework, in which both aggressive and prosocial responses to exclusion can occur in the reflective stage. The exact behavioural response depends on the context imposed by a range of personal and situational factors (Wesselmann et al., 2015). However, the model does not specify whether either response should be limited to any particular group of people. Instead, the general tendency to be more aggressive or prosocial is expected to be elevated in order to recover from the psychological impact of the exclusion experience. In interpreting our own findings, we propose a simpler explanation of how people react to exclusion - people do not want to cooperate with someone who did not behave nicely towards them a few minutes earlier. In 
SOCIAL EXCLUSION AND DECISION MAKING

Experiments 1 and 2, we found that self-esteem, feelings of meaningfulness, control (only Experiment 1) and belonging were positively correlated with the amount people were willing to invest. Across all studies, however, we did not find any association between people's mood and cooperativeness.

An important implication of our result is that while exclusion may be hurtful and unpleasant on the psychological level, it is important to understand the limits that a given psychological state may have on one's behaviour. Whereas it is possible that prolonged and frequent experience of exclusion impacts on people's behaviour, a single event of ostracism may not be sufficient to impact on people's general willingness to cooperate with others. Our results show that individuals may be both resilient and willing to work with others after being excluded. Any attempts to support those who were excluded (for example in schools or at work) should be cognizant of the fact that a single experience of exclusion may not necessarily result in a broad behavioural change. At the same time, our results show that people are willing to retaliate against those who excluded them, even if such a behaviour is self-defeating. In the context of teams and organisations, retaliations against any individual team member may be detrimental to the overall team performance.

In three experiments, we used the same manipulation to induce feelings associate with social exclusion. While we were successful in producing a threat to basic psychological needs, it is theoretically possible that the lack of aggressive or prosocial responses towards strangers was driven by aspects of the experimental design itself (Shilling \& Brown, 2016; Wesselmann et al., 2015; Williams, 2009). Opportunities to interact with strangers could be viewed as an opportunity to re-affirm one's sense of belonging, which should encourage more cooperative behaviour. However, we did not observe any difference between excluded and included individuals in their investment behaviour with new partners. One possible explanation for this lack of difference is that our participants have already recovered from the 


\section{SOCIAL EXCLUSION AND DECISION MAKING}

experience of being rejected (via their "aggressive" and uncooperative behaviour towards Cyberball partners) when they were given the opportunity to interact with a stranger. An alternative interpretation is that our investment game was not regarded as a viable mechanism to recover and reaffirm one's need for belonging (Derfler-Rozin et al., 2010). However, past work shows a connection between need to belong and cooperation in social dilemmas similar to the investment games that we used in the present manuscript. The common theme of these tasks is that personal earnings are closely tied to the earnings of another player. Although most studies showed the inverse relation — that people who experience higher feelings of belonging cooperate more (De Cremer, 2002) — other studies have also shown that increased cooperation makes people feel more included (De Cremer \& Leonardelli, 2003; J. Lee \& Shrum, 2012). In the same line, trusting others (e.g., by entrusting them with money) can help to increase a feeling of belonging. Future research is needed to establish how different task characteristics promote specific cognitive strategies for dealing with the negative effects of social exclusion.

Despite the potential limitations listed above, our results do not align with the predictions derived from the need-threat framework. It would be wrong to assume that our experiments included a specific cue for a participant that would elicit a particular response to ostracism (seeking reconnection vs. aggression) (Ren et al., 2018). That is, if our task was conducive of either threat to control or belonging, then we would expect difference in cooperativeness when interacting with a stranger. Another interpretation, and one that is consistent with the recently proposed goal-driven redistribution theory by Shilling and Brown (2016), is that participants in our task were particularly aware of the social cues conveyed by the identity of the partner. The state of emotional alertness motivates people to act, but the choice of action depends on the cognitive appraisal of the available situational cues. According to the goal-driven redistribution theory, social cues take priority over other non- 


\section{SOCIAL EXCLUSION AND DECISION MAKING}

social cues. So in the case of our investment task, excluded individuals could pay close attention to the fact that they are presented with the opportunity to play with the person who excluded them, as well as a new player. This cue may provoke an aggressive response, which is characterized by a differentiation between the two players. In other words, the lack of cooperativeness may feel more like a punishment if it is contrasted with a cooperative behaviour towards others. Here, the selective uncooperativeness could be interpreted as a very targeted and elaborate form of aggressive behaviour. Taken together, our results could necessitate a different model, and the goal-driven redistribution theory provides one possibility.

Although our design was created to test multiple competing hypotheses, it is possible that our experiments were not perfectly suited for capturing the effects of social exclusion on the availability of cognitive resources. In fact, in a recent meta-analysis of 64 studies, Rand (2016) found that manipulations aimed at promoting the use of intuition over deliberation led to more cooperation only in non-strategic tasks, such as one shot prisoner's dilemma or one shot public goods games. In strategic games, such as investment games of the format similar to the ones used in the present experiments, promotions of intuition led to no change in cooperation. Although Rand (2016) did not consider studies that used social exclusion manipulations, it could be argued that our excluded individuals had fewer cognitive resources available to them, but that this did not promote a particular change in their investment behaviour. Future studies are necessary to establish whether social exclusion truly reduces the cognitive capacities of a decision maker, and whether such an effect can alter cooperation in strategic games. We note that our recent results are inconsistent with the very notion that social exclusion leads to a detriment in "intelligent thought" in the context of judgment and decision-making tasks (cf. Juanchich et al., 2018). Excluded participants performed as well in 
SOCIAL EXCLUSION AND DECISION MAKING

the investment game as included participants, indicating that they were as capable as included participants of marshalling their cognitive resources to make their decisions.

Future work should establish whether cooperativeness following social exclusion may be dependent on the exclusion paradigm itself. For comparability, we relied entirely on the Cyberball paradigm alone in the present study. However, some of the most profound findings of aggressive responses following exclusion come from studies that used a "future-alone" paradigm (Twenge et al., 2007). This finding makes sense in relation to the need-threat framework, as imagining being alone in the future makes the need for control (or lack of it) particularly salient (for a comparison of methodologies see Bernstein \& Claypool, 2012; Godwin et al., 2014).

In conclusion, our findings do not show that social rejection impacts the ability to make optimal decisions in a social context. Our data provide a nuanced view of the consequences of social exclusion on decision-making involving others. Excluded participants are more cautious investors when they have reason to believe that they are interacting with an uncooperative individual.

\section{Open Practices}

The experiments reported in this article earned Open Materials and Open Data badges for transparent practices. All datasets and materials are available on the Open Science Framework: osf.io/yw9us. 


\section{References}

Achtziger, A., Alós-Ferrer, C., \& Wagner, A. K. (2016). The impact of self-control depletion on social preferences in the ultimatum game. Journal of Economic Psychology, 53, 116. https://doi.org/10.1016/j.joep.2015.12.005

Ayduk, O., Gyurak, A., \& Luerssen, A. (2008). Individual differences in the rejectionaggression link in the hot sauce paradigm: The case of Rejection Sensitivity. Journal of Experimental Social Psychology, 44, 775-782.

https://doi.org/10.1016/j.jesp.2007.07.004

Baumeister, R. F., DeWall, C. N., Ciarocco, N. J., \& Twenge, J. M. (2005). Social exclusion impairs self-regulation. Journal of Personality and Social Psychology, 88, 589-604. https://doi.org/10.1037/0022-3514.88.4.589

Baumeister, R. F., Twenge, J. M., \& Nuss, C. K. (2002). Effects of social exclusion on cognitive processes: anticipated aloneness reduces intelligent thought. Journal of Personality and Social Psychology, 83, 817-827. https://doi.org/10.1037//00223514.83.4.817

Berg, J., Dickhaut, J., \& McCabe, K. (1995). Trust, reciprocity, and social history. Games and Economic Behavior, 10, 122-142. https://doi.org/10.1006/GAME.1995.1027

Bernstein, M. J., \& Claypool, H. M. (2012). Not all social exclusions are created equal: Emotional distress following social exclusion is moderated by exclusion paradigm. Social Influence, 7, 113-130. https://doi.org/10.1080/15534510.2012.664326

Bouwmeester, S., Verkoeijen, P. P. J. L., Aczel, B., Barbosa, F., Bègue, L., Brañas-Garza, P., 
SOCIAL EXCLUSION AND DECISION MAKING

... Wollbrant, C. E. (2017). Registered replication report: Rand, Greene, and Nowak (2012). Perspectives on Psychological Science, 12, 527-542.

https://doi.org/10.1177/1745691617693624

Buckley, K. E., Winkel, R. E., \& Leary, M. R. (2004). Reactions to acceptance and rejection: Effects of level and sequence of relational evaluation. Journal of Experimental Social Psychology, 40, 14-28. https://doi.org/10.1016/S0022-1031(03)00064-7

De Cremer, D. (2002). Respect and cooperation in social dilemmas: The importance of feeling included. Personality and Social Psychology Bulletin, 28, 1335-1341. https://doi.org/10.1177/014616702236830

De Cremer, D., \& Leonardelli, G. J. (2003). Cooperation in social dilemmas and the need to belong: The moderating effect of group size. Group Dynamics: Theory, Research, and Practice, 7, 168-174. https://doi.org/10.1037/1089-2699.7.2.168

Declerck, C. H., Boone, C., \& Emonds, G. (2013). When do people cooperate? The neuroeconomics of prosocial decision making. Brain and Cognition, 81, 95-117. https://doi.org/10.1016/J.BANDC.2012.09.009

Derfler-Rozin, R., Pillutla, M., \& Thau, S. (2010). Social reconnection revisited: The effects of social exclusion risk on reciprocity, trust, and general risk-taking. Organizational Behavior and Human Decision Processes, 112, 140-150. https://doi.org/10.1016/j.obhdp.2010.02.005

DeWall, C. N., \& Bushman, B. J. (2011). Social acceptance and rejection. Current Directions in Psychological Science, 20, 256-260. https://doi.org/10.1177/0963721411417545

Godwin, A., MacNevin, G., Zadro, L., Iannuzzelli, R., Weston, S., Gonsalkorale, K., \& Devine, P. (2014). Are all ostracism experiences equal? A comparison of the 
SOCIAL EXCLUSION AND DECISION MAKING

autobiographical recall, Cyberball, and O-Cam paradigms. Behavior Research Methods, 46, 660-667. https://doi.org/10.3758/s13428-013-0408-0

Hawes, D. J., Zadro, L., Fink, E., Richardson, R., O’Moore, K., Griffiths, B., ... Williams, K. D. (2012). The effects of peer ostracism on children's cognitive processes. European Journal of Developmental Psychology, 9, 599-613.

https://doi.org/10.1080/17405629.2011.638815

Hillebrandt, H., Sebastian, C., \& Blakemore, S.-J. (2011). Experimentally induced social inclusion influences behavior on trust games. Cognitive Neuroscience, 2, 27-33. https://doi.org/10.1080/17588928.2010.515020

JASP Team. (2018). JASP.

Jeffreys, H. (1961). Theory of probability. Oxford: Oxford University Press.

Juanchich, M., Walasek, L., \& Sirota, M. (2018). Decision-makers are resilient in the face of social exclusion. British Journal of Psychology. https://doi.org/10.1111/bjop.12294

Lee, J., \& Shrum, L. J. (2012). Conspicuous consumption versus charitable behavior in Response to social exclusion: A differential needs explanation. Journal of Consumer Research, 39, 530-544. https://doi.org/10.1086/664039

Lee, M. D., \& Wagenmakers, E. J. (2013). Bayesian cognitive modeling : a practical course. Germany: Cambridge University Press.

Lohse, J. (2016). Smart or selfish - When smart guys finish nice. Journal of Behavioral and Experimental Economics, 64, 28-40. https://doi.org/10.1016/J.SOCEC.2016.04.002

Lyyra, P., Wirth, J. H., \& Hietanen, J. K. (2017). Are you looking my way? Ostracism widens the cone of gaze. Quarterly Journal of Experimental Psychology, 70, 1713- 
SOCIAL EXCLUSION AND DECISION MAKING

1721. https://doi.org/10.1080/17470218.2016.1204327

Maner, J. K., DeWall, C. N., Baumeister, R. F., \& Schaller, M. (2007). Does social exclusion motivate interpersonal reconnection? Resolving the "porcupine problem." Journal of Personality and Social Psychology, 92, 42-55. https://doi.org/10.1037/00223514.92.1.42

McCullough, M. E., Kurzban, R., \& Tabak, B. A. (2013). Cognitive systems for revenge and forgiveness. Behavioral and Brain Sciences, 36, 1-15. https://doi.org/10.1017/S0140525X11002160

Nezlek, J. B., Wesselmann, E. D., Wheeler, L., \& Williams, K. D. (2012). Ostracism in everyday life. Group Dynamics: Theory, Research, and Practice, 16, 91-104. https://doi.org/10.1037/a0028029

Rand, D. G. (2016). Cooperation, fast and slow. Psychological Science, 27, 1192-1206. https://doi.org/10.1177/0956797616654455

Rand, D. G., Greene, J. D., \& Nowak, M. A. (2012). Spontaneous giving and calculated greed. Nature, 489, 427-430. https://doi.org/10.1038/nature11467

Ren, D., Wesselmann, E. D., \& Williams, K. D. (2018). Hurt people hurt people: ostracism and aggression. Current Opinion in Psychology, 19, 34-38. https://doi.org/10.1016/j.copsyc.2017.03.026

Riva, P., Romero Lauro, L. J., DeWall, C. N., Chester, D. S., \& Bushman, B. J. (2015). Reducing aggressive responses to social exclusion using transcranial direct current stimulation. Social Cognitive and Affective Neuroscience, 10, 352-356. https://doi.org/10.1093/scan/nsu053 


\section{SOCIAL EXCLUSION AND DECISION MAKING}

Shilling, A. A., \& Brown, C. M. (2016). Goal-driven resource redistribution: An adaptive response to social exclusion. Evolutionary Behavioral Sciences, 10, 149-167. https://doi.org/10.1037/ebs0000062

Stevens, J. R., Volstorf, J., Schooler, L. J., \& Rieskamp, J. (2011). Forgetting Constrains the Emergence of Cooperative Decision Strategies. Frontiers in Psychology, 1, 235. https://doi.org/10.3389/fpsyg.2010.00235

Twenge, J. M., Baumeister, R. F., DeWall, C. N., Ciarocco, N. J., \& Bartels, J. M. (2007). Social exclusion decreases prosocial behavior. Journal of Personality and Social Psychology, 92, 56-66. https://doi.org/10.1037/0022-3514.92.1.56

Twenge, J. M., Baumeister, R. F., Tice, D. M., \& Stucke, T. S. (2001). If you can't join them, beat them: effects of social exclusion on aggressive behavior. Journal of Personality and Social Psychology, 81, 1058-1069. Retrieved from http://www.ncbi.nlm.nih.gov/pubmed/11761307

Verkoeijen, P. P. J. L., \& Bouwmeester, S. (2014). Does intuition cause cooperation? PLoS ONE, 9, e96654. https://doi.org/10.1371/journal.pone.0096654

Walasek, L., Matthews, W. J. W. J., \& Rakow, T. (2015). The need to belong and the value of belongings: Does ostracism change the subjective value of personal possessions? Journal of Behavioral and Experimental Economics , 58, 195-204. https://doi.org/10.1016/j.socec.2015.04.012

Warburton, W. A., Williams, K. D., \& Cairns, D. R. (2006). When ostracism leads to aggression: The moderating effects of control deprivation. Journal of Experimental Social Psychology, 42, 213-220. https://doi.org/10.1016/j.jesp.2005.03.005

Watson, D., Clark, L. A., \& Tellegen, A. (1988). Development and validation of brief 
SOCIAL EXCLUSION AND DECISION MAKING

measures of positive and negative affect: the PANAS scales. Journal of Personality and Social Psychology, 54, 1063-1070. Retrieved from

http://www.ncbi.nlm.nih.gov/pubmed/3397865

Wesselmann, E. D., Ren, D., \& Williams, K. D. (2015). Motivations for responses to ostracism. Frontiers in Psychology, 6, 40. https://doi.org/10.3389/fpsyg.2015.00040

Williams, K. D. (2007). Ostracism. Annual Review of Psychology, 58, 425-452. https://doi.org/10.1146/annurev.psych.58.110405.085641

Williams, K. D. (2009). Chapter 6 Ostracism. A Temporal Need-Threat Model. In Advances in Experimental Social Psychology (1st ed., Vol. 41, pp. 275-314). Elsevier Inc. https://doi.org/10.1016/S0065-2601(08)00406-1

Williams, K. D., \& Jarvis, B. (2006). Cyberball: a program for use in research on interpersonal ostracism and acceptance. Behavior Research Methods, 38, 174-180. Retrieved from http://www.ncbi.nlm.nih.gov/pubmed/16817529

Williams, K. D., \& Nida, S. A. (2011). Ostracism: Consequences and coping. Current Directions in Psychological Science, 20, 71-75.

https://doi.org/10.1177/0963721411402480

Zadro, L., Williams, K. D., \& Richardson, R. (2004). How low can you go? Ostracism by a computer is sufficient to lower self-reported levels of belonging, control, self-esteem, and meaningful existence. Journal of Experimental Social Psychology, 40, 560-567. https://doi.org/10.1016/j.jesp.2003.11.006 
SOCIAL EXCLUSION AND DECISION MAKING

\begin{abstract}
APPENDIX
Appendix A. The Cyberball post-experiment questionnaire used in Experiments 1-3.

Appendix B. Instructions for the money game used in Experiments 1-3.

Appendix C. Correlational analysis comparing the association between money earned and psychological needs among excluded and included individuals.
\end{abstract}


Appendix A. The Cyberball post-experiment questionnaire used in Experiments 1-6

a) Measure of mood: 10 item PANAS (Mackinnon, et al., 1999; Watson, et al., 1988) This scale consists of a number of words that describe different feelings and emotions. Read each item and then indicate to what extent you were experiencing them during the Cyberball game you played earlier. (5-point Likert scale from 'not at all' to 'completely').

Enthusiastic
Determined
Excited
Inspired
Alert
Scared
Afraid
Upset
Distressed
Nervous

b) Measure of the four fundamental needs (Zadro et al., 2004)

For each question, please click the number that best represents the feelings you were experiencing during the Cyberball game you played earlier. (5-point Likert scale from 'not at all' to 'very much').

- Sense of belonging

I felt disconnected

I felt rejected

I felt like an outsider

- Control

I felt I had control over the course of the interaction

I felt powerful

I felt superior

- Meaningful existence

I felt non-existent

I felt meaningless

I felt invisible

- Self-esteem

I felt good about myself

I felt liked

My self-esteem was high

c) Social exclusion perception 
For the next two questions, please tick the number that best represents the thoughts you had during the Cyberball game you played earlier. (5-point Likert scale from 'not at all' to 'very much').

- I felt included

- I felt excluded

Assuming you would receive the ball $33 \%$ of the time if everyone received it equally, what percentage of the throws did you receive? (Type a number between 0 and 100.) 


\section{Appendix B. Instructions for the investment game}

You will now play 10 rounds of a game in which you can earn money: the money game.

You will play with two of your fellow students. You will play the first five rounds with Jeff.

You will then play the other five rounds with Matt, with whom you also played the Cyberball game.

Your goal is to have as much money as possible at the end of the game.

To encourage you to play well, we will pay the actual earnings of one round of the game to three of the participants in this study. The winners will be randomly selected among you and could earn up to $£ 9$ in cash!

\section{Here are the rules of the game:}

1. In each round, you will be given an initial sum of money (between $£ 4$ and $£ 6$ ).

2. Your job is to decide how much of this money you want to transfer to the other player.

You can transfer any amount you want: from nothing $(£ 0)$ to all of it.

3. The money you transfer to the other player will be tripled before it is given to him.

4. Then, the other player will decide how much he gives back to you. The other player can either keep all of the money or share some of it with you.

\section{Here are some examples of what may happen:}

- You receive $£ 5$. You decide to keep $£ 5$ and transfer $£ 0$. The other player accordingly receives $£ 0$. At the end of the round, you own $£ 5$ and the other player owns $£ 0$.

- You receive $£ 6$. You decide to keep $£ 3$ and transfer $£ 3$. The other player accordingly receives $£ 9(£ 3 * 3)$. The other player has decided to keep all of the money. At the end of the round, you own $£ 3$ and the other player owns $£ 9$.

- You receive $£ 4$. You decide to keep $£ 0$ and transfer $£ 4$. The other player accordingly receives $£ 12(£ 4 * 3)$. The other player decides to share the money evenly with you and sends you back $£ 6$. At the end of the round, you own $£ 6$ and the other player owns £6.

\section{Make sure you understand the rules of the game. You will not be able to read the}

\section{instructions again afterwards.}

Ready to play?

If yes, press 'next' below.

If not, please read the instructions again. 
SOCIAL EXCLUSION AND DECISION MAKING

Appendix C. Correlational analysis comparing the association between money earned and psychological needs among excluded and included individuals.

\section{Experiment 1}

The correlations between money earned with the unknown player (pale grey) and the Cyberball player (dark grey) and the social exclusion manipulation check (perception of exclusion, needs and mood) are displayed in Figure S1. The slope of the regression lines for the unknown player is fairly flat, whereas the one for the Cyberball player is steeper. When participants invested with the Cyberball player, the correlations show a negative relation between feelings of exclusion and performance and a positive relation between belonging, self-esteem, control, life meaning and mood and performance. Pearson correlations showed that the mean earnings with the unknown player did not correlate with any of the social exclusion checking variables, $r$ s between $|<.01|$ and $|.13|$, all $p \mathrm{~s}>.05$. In contrast, the mean earnings with the former Cyberball player were statistically significantly correlated, $|.13|<r s$ $<|.30|($ all $p$ s $<.05$ except for mood, for which $p=.070)$.

$<$ Insert Figure S1 about here> 

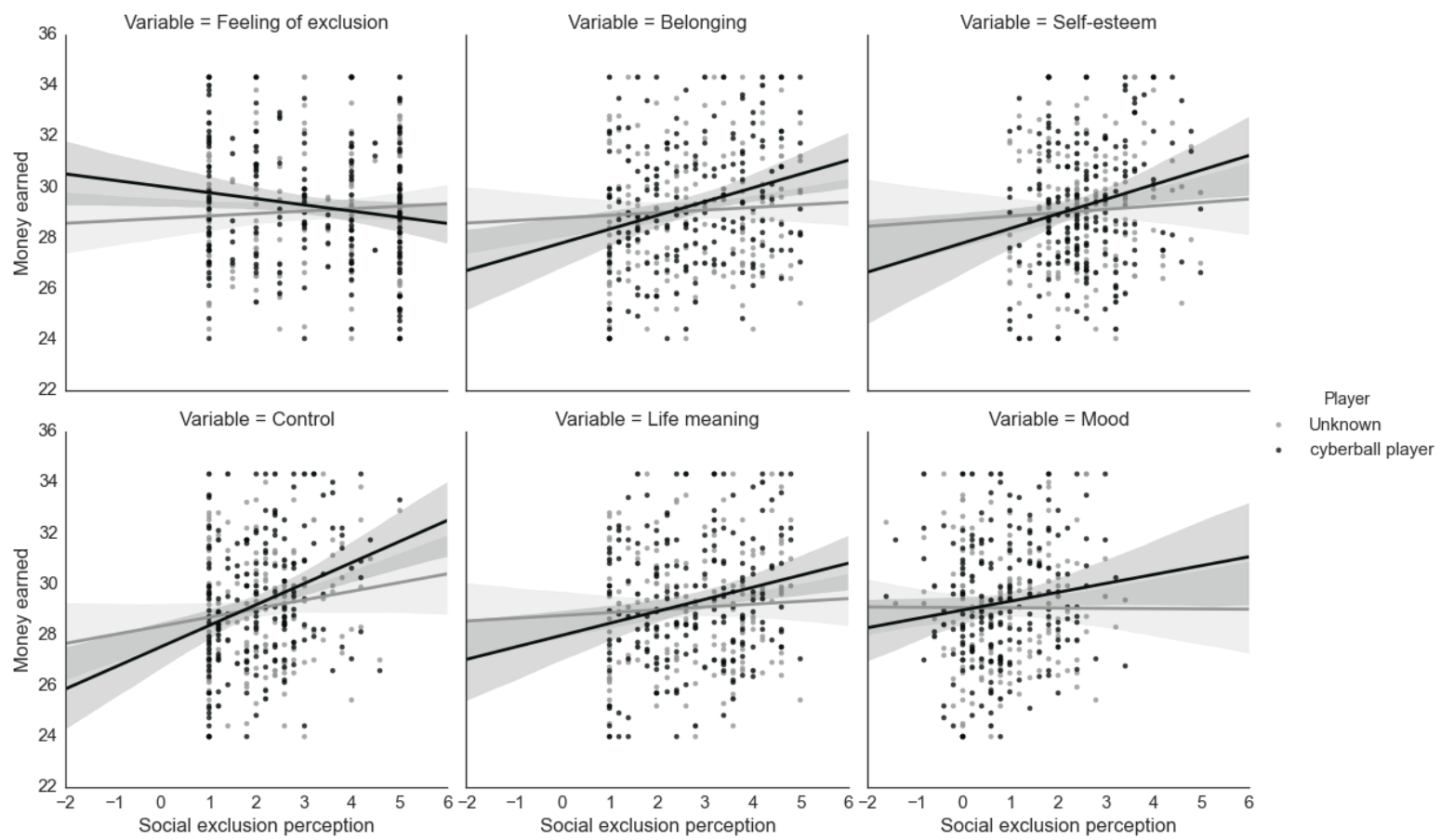

Figure S1. Relations between social exclusion perceptions and money earned with the unknown partner and the former Cyberball player in the cooperative version of the investment game (Experiment 1).

\section{Experiment 2}

The correlations between money earned with the investment game partners and the social exclusion perceptions are shown in Figure S2. The regression line was flatter for the unknown decision-making partner than for the Cyberball player indicating that perception of exclusion was not related to performance in this instance. The results of Pearson's correlations confirm this trend and did not show any significant correlation with any of the social exclusion checking variables, $|.03|$ for mood, to $|.13|$ for life meaning, all $p s>.05$. In contrast, the mean earnings with the former Cyberball player were statistically significantly correlated. Pearson's $r$ s ranged from $|.09|$ for control, to $|.31|$ for perception of exclusion, all $p s<.05$ except for feelings of control and mood, where $p=.340$ and .217 .

< Place Figure S2 about here > 

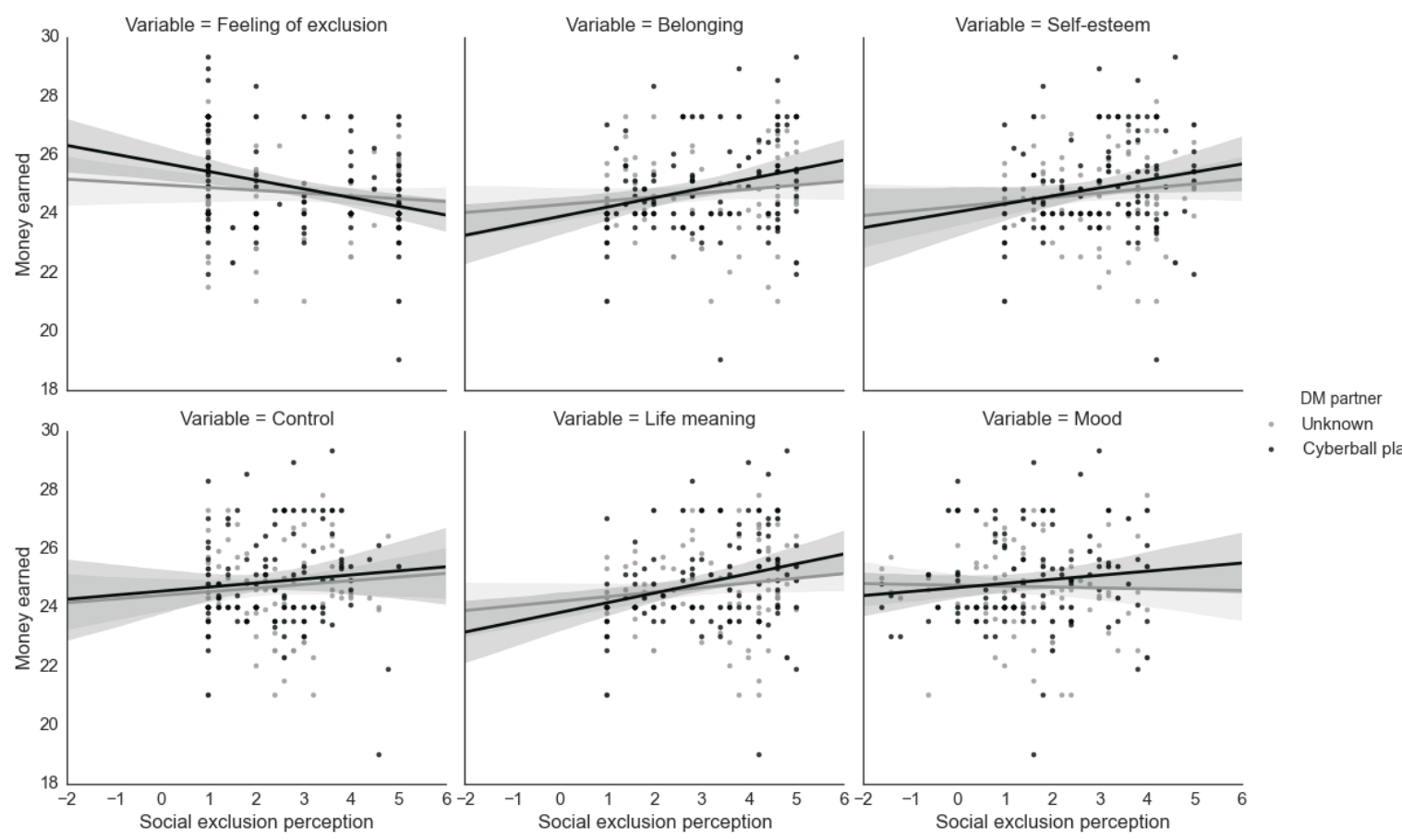

Unknown Cyberball player

Figure S2. Relations between social exclusion perceptions and money earned with the unknown partner and the former Cyberball player in Experiment 2.

\section{Experiment 3}

The correlations between money earned with the unknown partner and the known partner and the social exclusion manipulation check of social exclusion (perception of exclusion, needs and mood) are shown in Figure S3. The results revealed that the mean earnings with the unknown and the known partner were not correlated with the social exclusion checking variables (all $p \mathrm{~s}>.05)$.

< Place Figure S3 about here > 

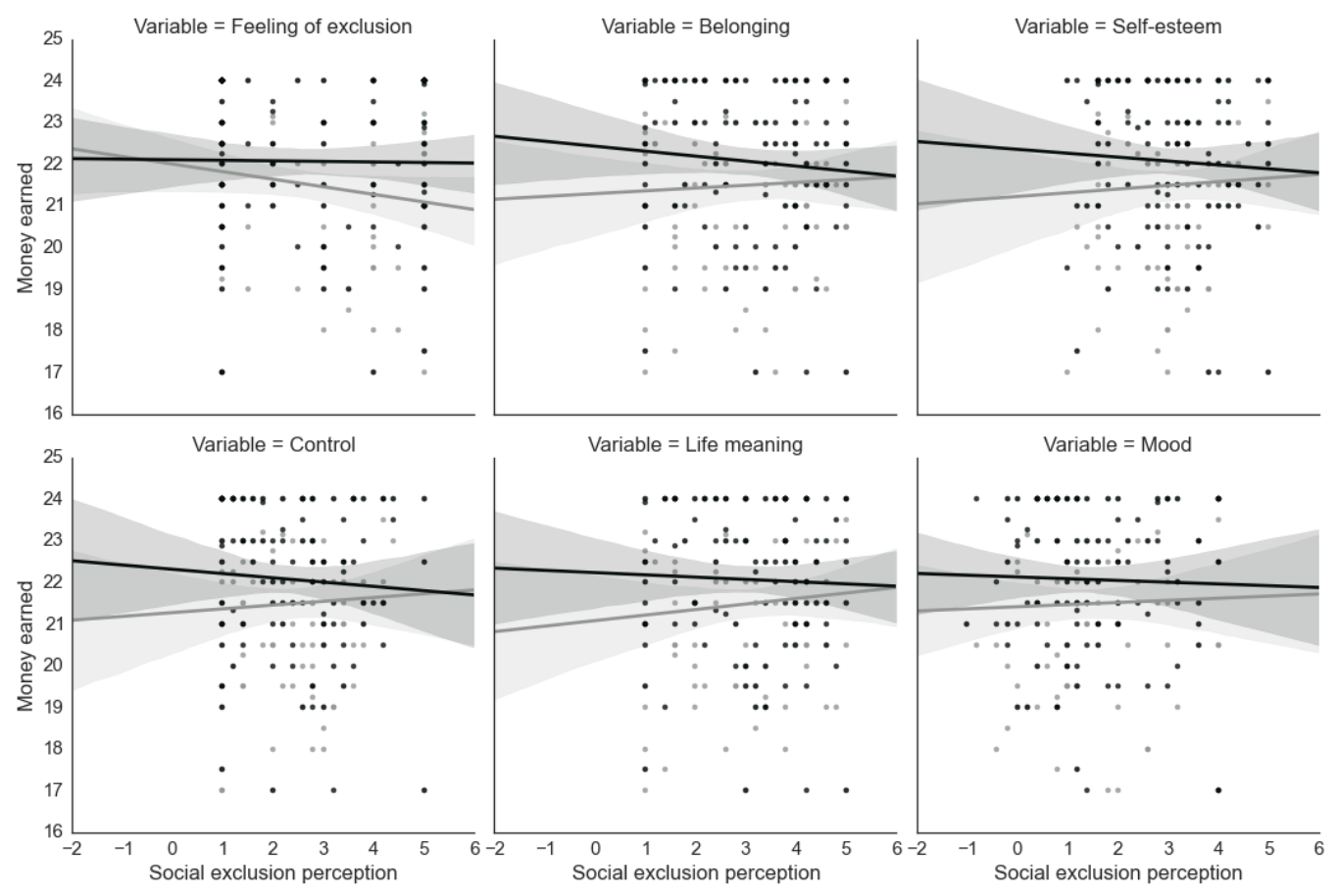

Figure S3. Relations between social exclusion perceptions and money earned with the unknown partner and the former Cyberball player in the uncooperative version of the investment game (Experiment 3). 